\title{
A pós-graduação e a pesquisa no Serviço Social latino-americano: uma primeira aproximação
}

\section{Postgraduation and research in the Latin American \\ Social Services: a preliminary approach}

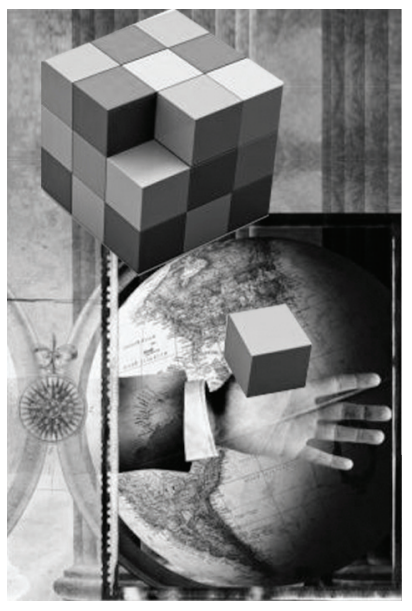

\section{Carlos Montaño*}

Resumo: O artigo visa apresentar a sistematização dos dados sobre pós-graduação e pesquisa nos países hispano-americanos, a partir de documentos apresentados em dois eventos latino-americanos de pós-graduação. O objetivo é estimular a articulação, os convênios e o intercâmbio entre as unidades de ensino brasileiras e as dos demais países do subcontinente latino-americano.

Palavras-chave: Serviço Social na América Latina. Pesquisa. Pós-graduação. Relações internacionais.

\begin{abstract}
This article presents the systematization of data on postgraduation and research in Spanish American countries. Such systematization was done from documents submitted in two Latin American postgraduation events. The goal is to stimulate the joint ventures, the agreements and the exchanges among Brazilian and other Latin American colleges.
\end{abstract}

Keywords: Social Work in Latin America. Search. Postgraduate. International relations.

* Doutor em Serviço Social e professor associado da Universidade Federal do Rio de Janeiro (UFRJ), RJ, Brasil; conferencista e professor visitante em diversos países latino-americanos; autor dos livros: $A$ natureza do Serviço Social (Cortez), Microempresa na era da globalização (Cortez), Terceiro Setor e questão social (Cortez, 2002) e Estado, classe e movimento social (em coautoria, Cortez). É coordenador da Biblioteca Latinoamericana de Servicio Social (Cortez). Foi membro da direção executiva da Alaeits (2006-09) e coordenador nacional de relações internacionais da Abepss (gestões 2009-10 e 2011-12). E-mail: <montano@ess.ufrj.br>. 


\section{Introdução}

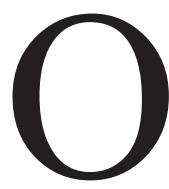

Serviço Social é uma profissão historicamente jovem, tendo sua gênese vinculada aos serviços e políticas sociais (Iamamoto, in Iamamoto e Carvalho, 1995) desenvolvidos na fase monopolista do capitalismo (Netto, 1992). Se para os países centrais isto ocorre na virada do século XIX para o XX, na nossa região isto ocorre mais tardiamente (Carvalho, in Iamamoto e Carvalho, 1995, Castro, 1993), com as experiências tardias e precárias de desenvolvimento de um "Estado social" ou dito "populista".

Não obstante sua juventude, a profissão na América Latina, fundamentalmente após a chamada Reconceituação, não esconde sua constante procura por um pensamento crítico e pelo compromisso com as "causas populares". Esta procura não ocorre de forma tranquila e sem problemas. Vejamos.

$\mathrm{Na}$ Reconceituação latino-americana o Serviço Social produz um salto qualitativo ao incorporar teoria, tanto proveniente das Ciências Sociais quanto do marxismo. Porém o faz, em geral, da seguinte forma:

- unidade na diversidade - ao pensar na América Latina e no desenvolvimento e produção do Serviço Social nesse contexto, encontramos uma "unidade na diversidade". Por um lado, diferentes processos histórico-políticos constituíram em cada país diversas estruturas produtivas, seus Estados, suas relações sociais, derivando no campo profissional em graus diversos de desenvolvimento, de inserção acadêmica e laborativa, de organizações profissionais e legitimidades sociais. No entanto, os fundamentos profissionais dão certa unidade: trata-se de países periféricos, com relativa semelhança como os processos de independentização, o chamado "populismo", o "desenvolvimentismo", as ditaduras militares, o neoliberalismo, os processos de lutas sociais e, na profissão, o chamado Movimento de Reconceituação;

- débil teoricamente - recorrendo não aos fundamentos e aos principais autores, mas preponderantemente a textos de divulgação, de intérpretes e autores secundários, bem como a manuais;

- indiferenciada - sem diferenciar as teorias das "ciências sociais particulares" da teoria marxista. Isto conduz a outros dois aspectos marcantes;

- acrítica - sem distinguir os fundamentos, as orientações e os valores que sustentam as diversas correntes das teorias sociais e dos diferentes autores;

- eclética - processando em geral uma suposta conciliação de teorias sem se atentar para o antagonismo nos seus fundamentos, valores e orientações; 
- esvaziada - tendo em muitos casos o esvaziamento de conteúdos, ao utilizar termos de uma teoria social com conteúdos de outra (exemplos são a perspectiva marxista de "totalidade" tornada "perspectiva de globalidade"; a "dialética" marxista transformada em "visão dialógica"; a "tese-antítese-síntese" hegelo-marxiana como "Assistência Social-Serviço Social-Trabalho Social"; a perspectiva de "revolução" em "mudança social"; "consciência de classe" em "conscientização socioeducativa"; a "classe" em "povo", entre tantas outras categorias e perspectivas);

- reducionista - com essas características gerais, a produção teórica na profissão tem se orientado para sistematizações de práticas e a elaboração manuais. Assim se procedeu não apenas com a teoria marxista (Quiroga, 1991), mas com o positivismo, com a fenomenologia, com o funcionalismo e o sistemismo etc.

Após a Reconceituação, e especialmente após os processos ditatoriais na América Latina e a "reinstitucionalização" democrática, aquela "unidade na diversidade" aprofunda o fosso entre o desenvolvimento profissional brasileiro e o hispano-americano (ver Montaño, 2008, p. 133-140). O desenvolvimento acadêmico, político-corporativo e teórico (nas pós-graduações, na produção bibliográfica) segue caminhos diferentes: enquanto as estratégias nos países hispano-americanos nas saídas da ditaduras (devastadoras da academia e particularmente do Serviço Social) tenderam a ser a do "retorno ao passado" - a restauração de autoridades, professores, curriculums e bibliografia, anteriores às ditaduras (Idem, p. 134), o caminho seguido no Brasil foi diferente: a consolidação das suas entidades corporativas (CFESS/Cress, Abepss, Enesso); o desenvolvimento da sua pós-graduação, se constituindo como área de conhecimento; a atualização teórica e significativa da produção bibliográfica (desenvolvendo uma verdadeira inflexão em diversas questões; Idem, p. 136-140); ${ }^{1}$ o desenvolvimento de um Projeto Ético-Político.

Este processo está longe ainda de se constituir uma realidade generalizada nos países hispano-americanos e em outras regiões, nos anos 1990 e ainda nos anos 2000. Como já afirmamos (Abepss, 2009, p. 12-3):

1. Em questões como: a compreensão crítica da natureza, fundamentos e papel social do Serviço Social; a avaliação crítica sobre o debate metodológico no Serviço Social; a compreensão crítica do sistema social capitalista, do papel do Estado e da função das políticas sociais; a compreensão crítica da crise capitalista e seu enfrentamento pelo capital: a ofensiva neoliberal; a compreensão crítica e atualizada do papel social da profissão no atual contexto de hegemonia neoliberal, e os desafios postos para o assistente social. 
O Serviço Social, no plano internacional, está ainda absorvendo [as transformações ocorridas no mundo desde a Reconceituação] para se reestruturar como profissão, ora se adaptando à nova realidade, ora contestando as perdas de direitos sociais e enfrentando a hegemonia neoliberal. Cada região, cada país, apresenta estratégias diversas, formas de organização diferentes, processos de formação e objetos de estudos diversificados, assim como perspectivas variadas para lidar com a nova conjuntura - a organização internacional de assistentes sociais, a Fits (Federação Internacional de Trabalhadores Sociais), está redefinindo o "significado" da profissão de Serviço Social; diversas unidades acadêmicas nos variados países estão reestruturando seus currículos e criando programas de pós-graduação; os conselhos, colégios e associações profissionais estão estudando as mudanças nos mercados de trabalho profissional, definindo ou redefinindo os códigos de ética, a legislação, as formas de organização corporativa e suas alianças interinstitucionais.

Nos países europeus, onde em geral o Serviço Social já tinha um nível fundamentalmente técnico, o "Acordo de Bolonha" está marcando a reestruturação na formação e na pós-graduação universitárias: graduação e mestrado não podem superar (juntos) o período de cinco anos, devem se criar "saídas curtas" na formação e ainda promover os cursos a distância, entre outras determinações. Postulados do "acordo" europeu aplicados na América Latina sem acordo!

Nos Estados Unidos, com uma tradição profissional direcionada fortemente para a ação terapêutica, clínica, já consolidada há muito tempo, a graduação está voltada em geral meramente para atender ao mercado, enquanto a pós-graduação tem um caráter profissionalizante, não acadêmico.

Na América Latina o Serviço Social vive uma realidade peculiar. A vasta diversidade dos países e regiões se articula com uma unidade na condição de países periféricos, ex-colônias, com uma forte presença multiétnica e multicultural — indígenas, afrodescendentes, imigrantes dos países colonialistas etc. - , seu precário e tardio desenvolvimento industrial e estatal, suas ditaduras militares, seus processos de lutas sociais, a aplicação do Consenso de Washington por governos neoliberais.

Ainda mais, no caso do Serviço Social, a particularidade do chamado movimento de Reconceituação e sua forte influência até hoje na maioria dos países, que promoveu um importante requestionamento profissional no seu momento, mas que na contemporaneidade se mostra incapaz de dar respostas adequadas às novas questões com que se defronta a profissão. Os diversos países do subcontinente estão se subsidiando em diferentes fontes bibliográficas: ora nos textos da reconceituação, ora na literatura norte-americana (e suas perspectivas funcionalista, sistêmica, pragmatista, terapêutica), ora na bibliografia antropológica, sociológica, psicológica, da administração etc., ora em textos profissionais atuais, alguns de cunho mais crítico, particularmente na produção fundamentalmente brasileira, argentina e chilena.

A Abepss propõe-se hoje a contribuir com esse processo. Trataremos a seguir, após a caracterização do papel da Abepss nas relações internacionais, das condições 
da pós-graduação e da pesquisa no Serviço Social latino-americano, particularmente nos países de língua hispânica.

\section{A Abepss e as relações internacionais}

As relações internacionais sempre foram um campo importante para o Serviço Social brasileiro e para a Abepss. Prova disso é a forte presença do debate brasileiro nos eventos internacionais (desde meados dos anos 1960), na revista Acción Crítica (da Alaets-Celats, desde 1979), no mestrado latino-americano em Honduras, coordenado pelo Celats (desde 1978), além da participação intensa nos diversos cargos na Alaets (Associação Latino-Americana de Escolas de Trabalho Social) e no Celats (Centro Latino-Americano de Trabalho Social): Seno Cornely, Leila Lima Santos, Consuelo Quiroga, Josefa Batista Lopes, Beatriz Abramides, Marieta Koike, Jussara Mendes, e mais recentemente, após a refundação da entidade em 2006, com o Brasil assumindo a primeira gestão da nova Alaeits (Associação Latino-Americana de Ensino e Pesquisa em Trabalho Social), entre 2006 e 2009, composta por Ana Elisabete Mota (presidente), Beatriz Abramides (secretária), Carlos Montaño (tesoureiro) e Inês Bravo, Serafim Paz e Elaine Behring (suplentes).

Já desde os anos 1990 o Brasil tem desenvolvido convênios entre a PUC-SP com a Universidad de La Plata (Argentina) e o Instituto Superior Miguel Torga (Coimbra, Portugal) e a UFRJ com a Universidad de la República (Montevidéu, Uruguai), levando seus mestrados aos países conveniados ou formando quadros docentes nos mestrados e doutorados no Brasil. Hoje são diversas as universidades brasileiras com convênios e acordos de intercâmbio.

No caso das entidades latino-americanas, a Alaets e o Celats, a partir da retirada do financiamento da Konrad Adenauer, em 1992, e da retomada dos processos de redemocratização na região, que levou à concentração dos esforços em reerguer as escolas em cada país, protagonizaram uma forte crise (financeira, legal e de legitimidade). O processo se alastra até 2006, quando, em evento mundial da IASW (Associação Internacional de Trabalho Social, entidade acadêmica), organizado em Santiago do Chile, a partir de propostas da delegação brasileira, na Assembleia de Alaets, foi aprovado o processo de refundação (ver $<$ http://www.ts.ucr.ac.cr/html/ alaeits/alaeits-es.htm $>$ ). A entidade latino-americana foi reestruturada e redefinida, seus objetivos, sua estrutura, seu estatuto, a partir da nova realidade. A Alaeits passou a ter um papel fundamentalmente articulador.

Na Abepss, a constituição da Coordenação de Relações Internacionais teve início na gestão 2007-08, sendo Marieta Koike sua primeira coordenadora. Assim, 
apesar de toda a experiência de intercâmbio internacional, a organização e a sistematização de uma política de relações internacionais é muito recente, e ainda está por ser constituída.

O Estatuto da Abepss, no seu artigo 26, sobre as competências das relações internacionais, aponta as seguintes atribuições: I) Propor a política de relações internacionais da entidade; II) Implementar a política de relações internacionais da entidade, em articulação com a Coordenação Nacional de Graduação e de Pós-Graduação; III) Organizar e manter atualizado o cadastro das experiências de relações internacionais realizadas no âmbito do ensino e da pesquisa na área de Serviço Social; IV) Incentivar e apoiar a articulação internacional do Serviço Social Brasileiro, nos níveis de graduação, pós-graduação e da pesquisa; V) Realizar estudos sistemáticos sobre as relações internacionais do Serviço Social brasileiro no mundo; VI) Incentivar e apoiar o intercâmbio de estudantes e professores de Serviço Social por meio de publicações e dos programas dos organismos de financiamento; VII) Organizar e manter atualizado cadastro de organismos financiadores de ensino e pesquisa em âmbito internacional; VIII) Incentivar o debate sobre o internacionalismo e de sua incidência no Serviço Social brasileiro.

É baseado nessas atribuições do Estatuto, e nas Diretrizes e Política de Ações para o biênio 2011-2012, apresentadas pela chapa eleita no Enpess (Rio de Janeiro, 9 de dezembro de 2010), que, no contexto da Reunião Ampliada da Abepss (28 e 29 de março de 2011), se deliberou como Plano de Trabalho para a área os seguintes objetivos:

1. criar um GT para elaboração da proposta de política intercâmbio e de relações internacionais da Abepss e para a sua implementação;

2. apoiar a Alaeits como instância articuladora do ensino e da pesquisa em Serviço Social na América Latina;

3. propiciar a internacionalização da área.

Neste último objetivo, e em concordância com o ponto III do artigo 26 do Estatuto, se define como uma das atividades: "Organizar uma base de dados sobre a graduação e os programas de pós-graduação e sobre as revistas estrangeiras".

É com o fim de contribuir com tal objetivo, de propiciar a internacionalização da área, na realização inicial desta atividade, que desenvolvemos a sistematização de dados apresentados neste artigo. Com eles, esperamos primeiramente subsidiar os trabalhos do GT (em processo de constituição), assim como, por outro lado, estimular e incentivar as experiências de intercâmbio e os convênios interinstitucionais. 


\section{A realidade da pós-graduação e da pesquisa}

O presente item visa apresentar a sistematização de dados e uma reflexão preliminar sobre a situação da pós-graduação e da pesquisa nos países hispano-americanos.

O objetivo é proporcionar uma primeira e necessariamente provisória visão da sua situação, procurando fundamentalmente com esse conhecimento estimular e promover intercâmbios, relações interinstitucionais e articulação de experiências.

Os dados aqui apresentados são obtidos dos seguintes eventos internacionais, em que foram realizadas reuniões com delegados de cada país do subcontinente onde existe pós-graduação em Serviço Social, apresentando relatórios sobre a situação nos seus países (ver os Quadros 1, 2 e 3):

1) I Encontro Latino-Americano de Pós-Graduação em Serviço Social (organizado pela ESS da UFRJ; Rio de Janeiro, 26 de julho de 2008);

2) XIX Seminário Latino-Americano de Escolas de Trabalho Social - Oficina de Pós-Graduação e Pesquisa (organizado pela Alaeits; Guayaquil, 6 outubro de 2009).

Algumas reflexões são também resultado de entrevistas e levantamento de dados realizados em diversas unidades de ensino da América Latina.

Estamos, neste texto, incorporando a realidade latino-americana com exceção do caso brasileiro. Consideramos nesta análise apenas os pós-strito sensu: mestrados e doutorados. Os mesmos foram classificados em três tipos: a) os específicos (realizados nas faculdades e escolas de Serviço ou Trabalho Social e com titulação em Serviço ou Trabalho Social, ou em áreas gerais mas com "saídas" ou "menções" em trabalho social); b) os vinculados (oferecidos pelas unidades de formação da profissão, mas orientados a subáreas pontuais, como política social, pesquisa, família, gestão social etc.); c) os orientados a áreas afins (podendo ou não ser realizados por unidades da profissão em parceria com outras disciplinas, como Ciências Sociais).

Existem dezesseis mestrados especificos em Serviço ou Trabalho Social (ou com saídas e menções na profissão) nos países hispano-americanos, distribuídos por dez países, nas três regiões da Alaeits (Cone-Sul/Andina/México-Centro América e Caribe). Na metade dos países hispano-americanos existe pós-graduação específica em Serviço Social, cobrindo todas as regiões; no entanto, a maioria deles está em três países nos extremos do subcontinente: Argentina, Chile e México.

Há hoje seis doutorados específicos em quatro países, sem nenhum doutorado na região Andina. Isto mostra um ainda insuficiente desenvolvimento de doutorados na área para contemplar os dezenove principais países hispano-americanos. 
A existência de pós-graduação em Serviço Social nos países hispano-americanos é na realidade muito recente. Dos 32 mestrados registrados, dois são do período de 1970-80 (Honduras e México-Nuevo León), sete da década de 1990 (sendo três específicos), e 23 são dos anos 2000 (onze específicos). Dos sete doutorados, com a exceção de um (México-Nuevo León), todos são posteriores a 2000.

Não obstante essa "juventude" dos pós, é possível observar, na diversidade dos variados programas, algumas características que poderiam nos ajudar identificar o "estado das artes" da pós-graduação em Serviço Social nos países hispano-americanos. Vejamos alguns aspectos:

- Poucas são as dissertações e/ou teses que viraram livro ou foram publicizadas de alguma forma, ficando a maior parte da produção restrita à circulação interna (como no caso de artigos nas revistas próprias dos programas). A exceção está nos países com maior concentração de mestrados: Chile, México e principalmente Argentina (onde a existência de grandes editoras permite maior publicação do produto das pesquisas de pós-graduação). Por tal motivo, parece razoável interpretar que os avanços das pesquisas pouco se revertem em crescimento e acúmulo do debate teórico na profissão; as novas pesquisas pouco incidem no debate profissional, ainda ancorado fortemente nas questões dos anos 1960-70.

- Na verdade, apenas duas grandes editoras publicam textos de Serviço Social nos países hispano-americanos: a Editora Espacio e a Lúmen-Humanitas, ambas da Argentina. A Cortez Editora tem também uma coleção de textos em espanhol dirigido ao público hispano-americano. O restante são pequenas editoras, fundamentalmente para a publicação de revistas. Ou seja, as possibilidades de publicização do produto das pesquisas é quase inexistente.

- Como resultado disto observamos (comprovado pela visita a diversas bibliotecas universitárias) que em muitos casos a bibliografia recorrente da profissão não é atualizada, remetendo fundamentalmente à produção da Reconceituação, ou quando atualizada é "externa" à profissão. Não obstante, deve-se salientar que este não é o caso da Argentina (com substantiva produção própria e atualizada), e de alguma maneira do Chile, Uruguai e Costa Rica, países (os quatro) com fortes laços com os programas de pós-graduação e com a bibliografia brasileiros - ora por convênios, ora por professores que cursaram pós no Brasil.

- Como regra geral, a realidade dos programas de pós-graduação, mesmo em universidades públicas, tem algum tipo de cobrança monetária dos alunos, não sendo gratuito. 
- Outra característica generalizada é a quase ausência de professores com dedicação exclusiva. Na maioria das unidades, a maior parte dos professores (incluídos os da pós-graduação) são "horistas", com dedicação parcial (apenas para as aulas). Como no caso brasileiro, esta não é a realidade das universidades públicas no México, Costa Rica e Porto Rico.

- Este fato incide na quase inexistência de núcleos de pesquisa institucionalizados, com carga horária docente, com infraestrutura acadêmica e com recursos para essa atividade. A pesquisa fica geralmente realizada a partir de esforços individuais e de forma extrainstitucional. Assim, a pesquisa avança muito lentamente.

- O fato está diretamente relacionado a que, diferentemente do Brasil, o Serviço Social não constitui uma "área de conhecimento" autônoma; e ainda, na maioria dos países não existem órgãos (governamentais ou privados) de regulação e promoção da pesquisa. Sabemos que no México, na Guatemala e em Porto Rico a pós-graduação e a pesquisa são acompanhadas por órgãos de regulação e promoção privados (vinculados a normas norte-americanas). Sobre este aspecto, seria necessário maiores informações para completar um quadro preciso.

- Por outro lado, é uma realidade a existência de diversos mestrados e até doutorados profissionalizantes; porém são necessários mais dados para poder quantificar o percentual desses em relação aos acadêmicos.

- Aspecto relevante e positivo é a enorme maioria de mestrados presenciais ( $90 \%$ dos que registraram este dado), contra $10 \%$ semipresenciais e nenhum registro de pós-graduação a distância (EAD). Não se tem registros deste aspecto para o doutorado.

- Observa-se uma variedade de temas tratados (como áreas de concentração, menções, ou linhas de pesquisa), entre os quais destacamos: História e Fundamentos do Serviço Social; Pesquisa; Metodologia e Intervenção Profissional; Política Social; Saúde; Família; Terapia Familiar (Sistêmica); Criança e Adolescente (Juventude); Mulher e Gênero; Adulto Maior (Gerontologia); Violência e Conflito Social; Gestão e Gerência Social; Desenvolvimento Humano e Social; Pobreza e Vulnerabilidade; Migração. Algumas precisões sobre esta questão. Primeiramente, observa-se ausência de objetos de pesquisa e debate mais estruturais, dos fundamentos da sociedade capitalista (que aparece muito lateralmente mas quase nunca como objeto sobre o qual deva/possa se debruçar um assistente social). Em segundo lugar, a análise dos programas de pós e uma exploração preliminar 
das revistas de cada unidade mostram-nos que cada país desenvolve fundamentalmente alguns temas mais recorrentemente: por exemplo, na Colômbia, os temas família, migração, violência e conflito; no México, metodologia, política social, família, etnia e questão indígena; na Costa Rica, gênero, gerência social; na Argentina, fundamentos e história do Serviço Social, saúde; no Chile: terapia familiar sistêmica, família, intervenção profissional.

- Outro aspecto relevante é que acompanhando o surgimento e o desenvolvimento deste aumento de pós-graduações em Serviço Social, a grande maioria das unidades de ensino promoveu a criação de revistas acadêmicas de Serviço Social. Sua divulgação e distribuição maciças resultam em um engodo, porém a existência dessas revistas na maioria dos países com pós é digna de menção, e uma realidade sobre a qual pode se estabelecer formas de intercâmbio e colaboração.

Esses dados e essas reflexões, ainda preliminares, mostram-nos um quadro otimista, mas problemático e desafiador, sobre a pós-graduação e a pesquisa no Serviço Social na América Latina, especificamente nos países hispano-americanos.

É otimista, pois na última década e meia os esforços para desenvolver programas de pós-graduação tiveram sucesso, levando quantitativamente a pós em Serviço Social a constituir uma realidade significativa. Otimista pela quantidade de revistas que acompanham esses esforços. Otimista pela dedicação (extrainstitucional) que é vertida por profissionais para desenvolver a pesquisa no Serviço Social. Também pela diversidade de temas (muitos dos quais coincidem com as áreas de interesses no Brasil), fundamentalmente voltados para as realidades com as quais os profissionais lidam nos seus países e regiões; pelo caráter eminentemente presencial da pós-graduação.

Problemático é por ser ainda uma pós-graduação muito jovem, com muito para desenvolver e consolidar: a formação e a qualificação de quadros docentes e pesquisadores para a pós; a necessária atualização bibliográfica; o enfrentamento da precariedade institucional na primazia de professores "horistas", da quase inexistência de estruturas institucionais de pesquisa, assim como na quase inexistência de órgãos de regulação e fomento da pós e da pesquisa.

Desafiador, no sentido da necessidade (e possibilidade) de promover experiências de intercâmbio, acordos e convênios entre unidades acadêmicas com pós e pesquisas consolidados com aqueles programas ainda "jovens".

É sobre esses desafios que trataremos no terceiro item deste breve texto. 


\section{Conclusão. Articulação, convênios e intercâmbio: uma necessidade e um desafio para o Serviço Social brasileiro}

Estes dados, e as reflexões aqui contidas, visam apresentar um ainda preliminar diagnóstico da situação atual da pós-graduação em Serviço Social na América Latina (aqui focando especificamente os países hispano-americanos), tendo por principal finalidade estimular, brindando alguns dados fundamentais, a elaboração de convênios, intercâmbios e articulações entre as unidades de ensino no Brasil com os programas de pós-graduação dos restantes países latino-americanos.

A articulação pode se desenvolver de diversas formas:

a) um convênio formal ("guarda-chuvas") entre as universidades (assinado pelos reitores envolvidos) e desdobrado em projeto(s) entre as unidades de Serviço Social. Nele pode se incluir o apoio de um programa já consolidado a outro ainda não consolidado ou a ser criado: assessorando o projeto de criação do programa, facilitando a mobilização dos professores, desenvolvendo o curso de mestrado ou doutorado na unidade não consolidada, recebendo alunos dessa unidade para a qualificação de quadros docentes etc. ${ }^{2}$

b) formas de intercâmbio (que não exigem necessariamente convênios "guarda-chuvas"), onde diversos programas podem promover: intercâmbio e/ou articulação de pesquisas (comparativas, complementares etc.); mobilidade docente ou de estudantes (para participar em cursos, estágios, eventos etc.); intercâmbio de revistas (tanto na distribuição dos exemplares, quanto na participação de professores nos conselhos editoriais internacionais, ou na publicação de artigos); realização de eventos interinstitucionais; participação conjunta em editais de promoção de atividades de cooperação etc.

Essas formas de articulação internacional entre os programas no Brasil e as unidades dos países hispano-americanos não só constituem um desafio para a própria consolidação dos pós-graduação no país, mas também contribuem com a ampliação dos horizontes de debate profissional e até da construção internacional do próprio Projeto Ético-Político da profissão.

Recebido em 23/8/2011 - Aprovado em 5/9/2011

2. Essas experiências já foram realizadas de alguma forma pela PUC-SP, UFRJ, UERJ, UFPE. 


\section{Referências bibliográficas}

ABEPSS. Apresentação. Temporalis, Brasília, Abepss, n. 18, 2009.

CASTRO, Manuel Manrique. História do Serviço Social na América Latina. São Paulo: Cortez-Celats, 1993.

IAMAMOTO, Marilda; CARVALHO, Raul. Relações sociais e serviço social no Brasil. São Paulo: Cortez-Celats, 1995.

MONTAÑO, Carlos. O serviço social na América Latina e o debate brasileiro. Em Pauta, Rio de Janeiro, n. 22, 2008.

NETTO, José Paulo. Capitalismo monopolista e serviço social. São Paulo: Cortez, 1992.

QUIROGA, Consuelo. Invasão positivista no marxismo: manifestações no ensino da Metodologia no Serviço Social. São Paulo: Cortez, 1991.

\section{Quadro 1}

Mestrados, doutorados e revistas dos programas de pós-graduação na América Latina

\begin{tabular}{|c|c|c|c|}
\hline PAÍS & MESTRADO & DOUTORADO & REVISTA \\
\hline Argentina & 5 (3 esp./1 vinculado/1 afim) & 4 (3 esp./1 afim) & 4 \\
\hline Chile & 5 (2 esp./2 vinculados/1 afim) & - & 3 \\
\hline Uruguai & 1 (especifico) & 1 (interdisciplinar) & 1 \\
\hline Colômbia & 1 (especifico) & - & 1 \\
\hline Peru & 2 (vinculados) & - & 1 \\
\hline Venezuela & 1 (vinculado) & - & 1 \\
\hline Costa Rica & 3 (1 específico/2 vinculados) & - & 2 \\
\hline Guatemala & 2 (1 esp./1 área afim) & 1 (especifico) & - \\
\hline Honduras & 1 (especifico) & - & - \\
\hline México & 7 (4 esp./3 vinculados) & 1 (específico) & 2 \\
\hline Nicarágua & 2 (vinculados) & - & - \\
\hline Panamá & 1 (especifico) & - & - \\
\hline Porto Rico & 1 (especifico) & 1 (específico) & 1 \\
\hline Total & 32 (16 esp./13 vinc./3 afins) & 8 (6 esp./1 interd./1 afim) & 16 \\
\hline
\end{tabular}


Quadro 2

Revistas dos programas de pós-graduação

\begin{tabular}{|c|c|c|}
\hline CIDADE & UNIVERSIDADE & REVISTA \\
\hline \multicolumn{3}{|c|}{ ARGENTINA } \\
\hline Córdoba & Univ. Nacional de Córdoba & $\begin{array}{l}\text { Rev. Conciencia Social } \\
\text { concienciasocial@ets.unc.edu.ar }\end{array}$ \\
\hline La Plata & Univ. de La Plata & $\begin{array}{l}\text { Rev. Escenarios } \\
\text { www.trabajosocial.unlp.edu.ar/escenarios.htm }\end{array}$ \\
\hline Rosário & Univ. Nal. Rosário & $\begin{array}{l}\text { Rev. Temas y Debates (Fac) } \\
\text { Rev. Cátedra Paralela (Esc) }\end{array}$ \\
\hline \multicolumn{3}{|c|}{ CHILE } \\
\hline Santiago & Pont. Univ. Católica de Chile & $\begin{array}{l}\text { Rev. de Trabajo Social } \\
\text { www.puc.cl/trabajosocial/html/re_publicaciones.htm }\end{array}$ \\
\hline Valparaíso & Univ. Valparaíso & $\begin{array}{l}\text { Rev. Sintesis } \\
\text { http://www.revistasintesis.cl/?secc=publicacion }\end{array}$ \\
\hline \multicolumn{3}{|c|}{ URUGUAI } \\
\hline Montevidéu & Univ. de la República & $\begin{array}{l}\text { Rev. Fronteras } \\
\text { http://www.rau.edu.uy/fcs/dts/publicacionesweb.htm }\end{array}$ \\
\hline \multicolumn{3}{|c|}{ COLÔMBIA } \\
\hline Bogotá & Univ. Nal. de Colombia & $\begin{array}{l}\text { Rev. de Trabajo Social } \\
\text { http://www.humanas.unal.edu.co/revista_tsocial/ } \\
\text { RegistroRevista.php }\end{array}$ \\
\hline \multicolumn{3}{|c|}{ PERU } \\
\hline Arequipa & Un. Nal. San Agustin Arequipa & Rev. de Trabajo Social \\
\hline \multicolumn{3}{|c|}{ VENEZUELA } \\
\hline Zulia-Maracaibo & Univ. de Zulia & Rev. Venezolana de Trabajo Social \\
\hline \multicolumn{3}{|c|}{ COSTA RICA } \\
\hline \multirow{2}{*}{ San José } & \multirow{2}{*}{ Univ. de Costa Rica } & $\begin{array}{l}\text { Rev. Costaricense de Trabajo Social } \\
\text { coltras@racsa.co.cr }\end{array}$ \\
\hline & & $\begin{array}{l}\text { Foro Sura } \\
\text { http://www.ts.ucr.ac.cr/bv/sura.php }\end{array}$ \\
\hline \multicolumn{3}{|c|}{ MÉXICO } \\
\hline $\begin{array}{l}\text { Monterrey- } \\
\text {-Nuevo. León }\end{array}$ & $\begin{array}{l}\text { Autónoma Nuevo León } \\
\text { (UANL) }\end{array}$ & $\begin{array}{l}\text { Rev.Perspectivas Sociales } \\
\text { mramor@ccr.dsi.uanl.mx } \\
\text { mramor@facts.uanl.mx } \\
\text { www.fts.uanl.mx/publicaciones/revistas.htm }\end{array}$ \\
\hline México - DF & $\begin{array}{l}\text { Autónoma de México } \\
\text { (UNAM) }\end{array}$ & Rev. de Trabajo Social \\
\hline \multicolumn{3}{|c|}{ PUERTO RICO } \\
\hline San Juan & Univ. de Puerto Rico & $\begin{array}{l}\text { Rev. Análisis } \\
\text { http://sociales.uprrp.edu/revistas-a.html }\end{array}$ \\
\hline
\end{tabular}




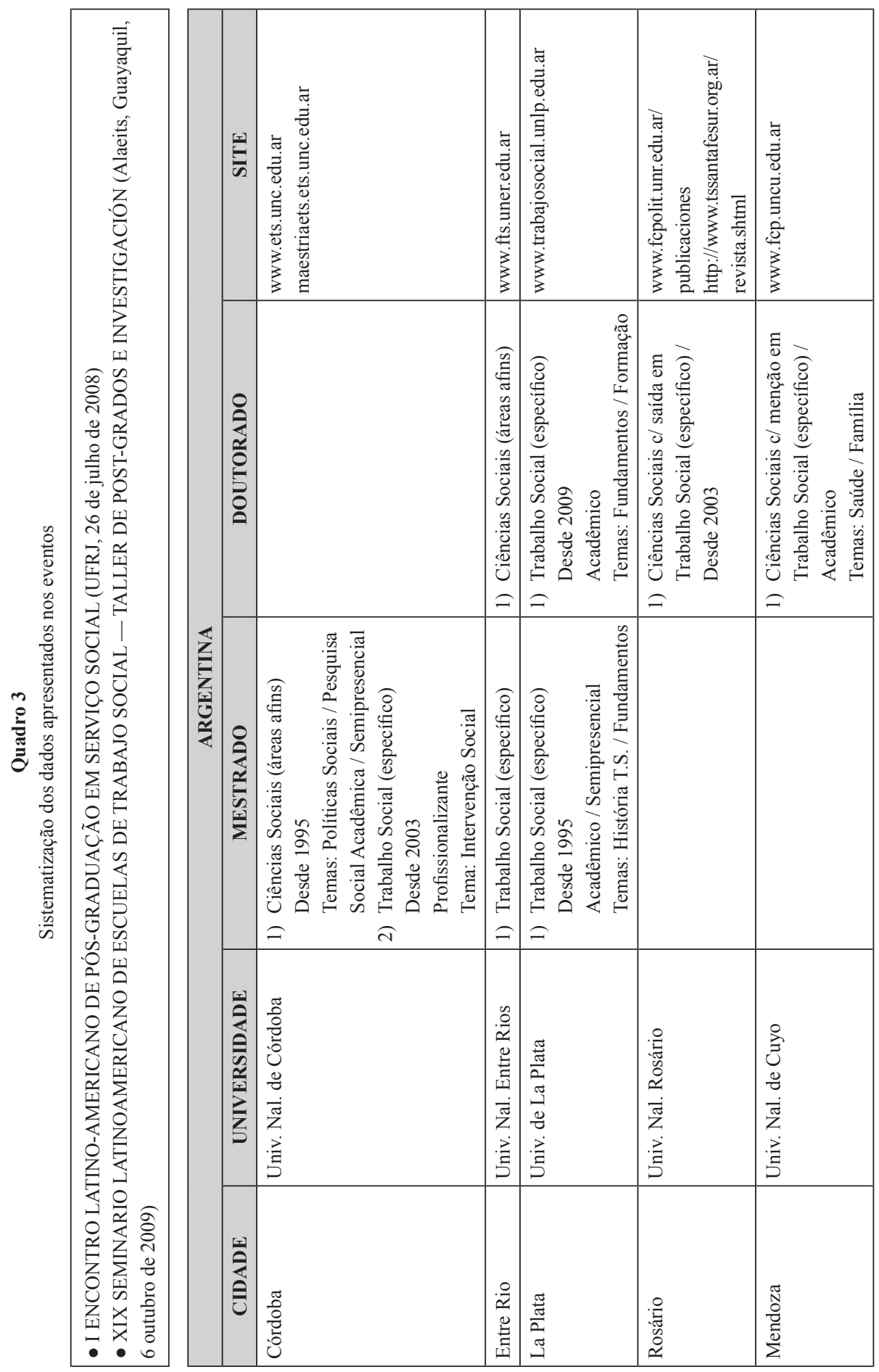

Serv. Soc. Soc., São Paulo, n. 108, p. 762-780, out./dez. 2011 


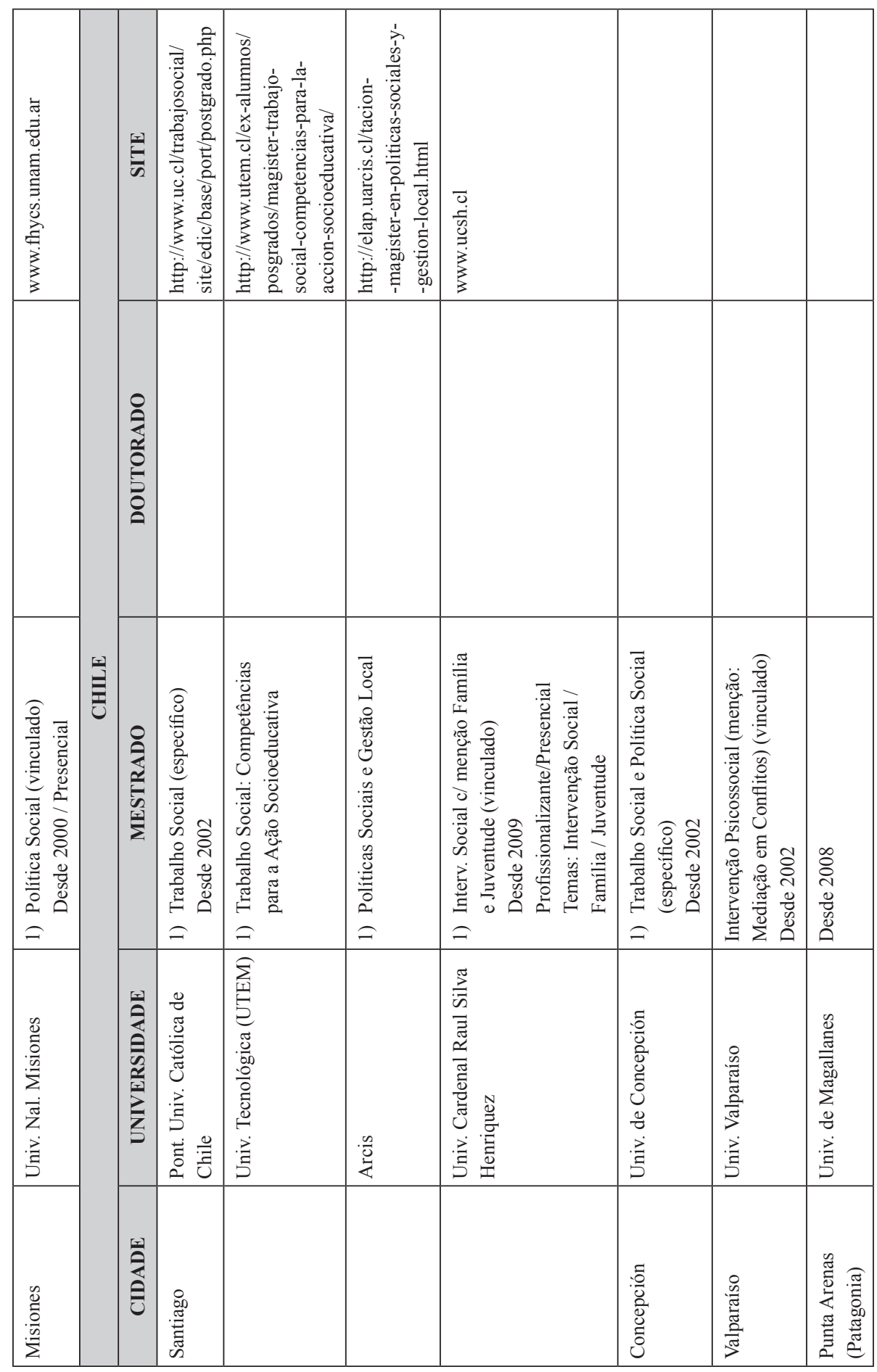




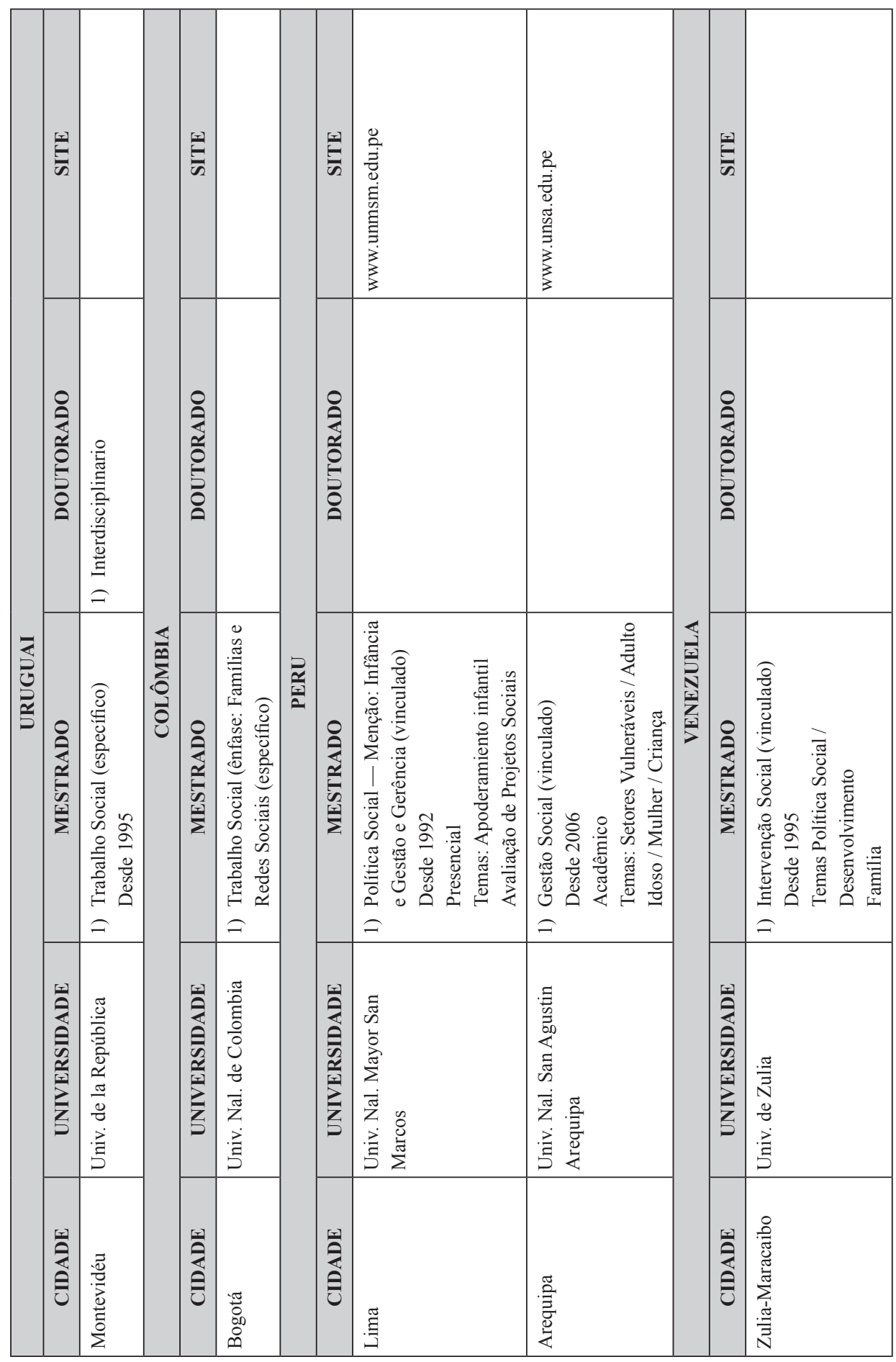

Serv. Soc. Soc., São Paulo, n. 108, p. 762-780, out./dez. 2011 


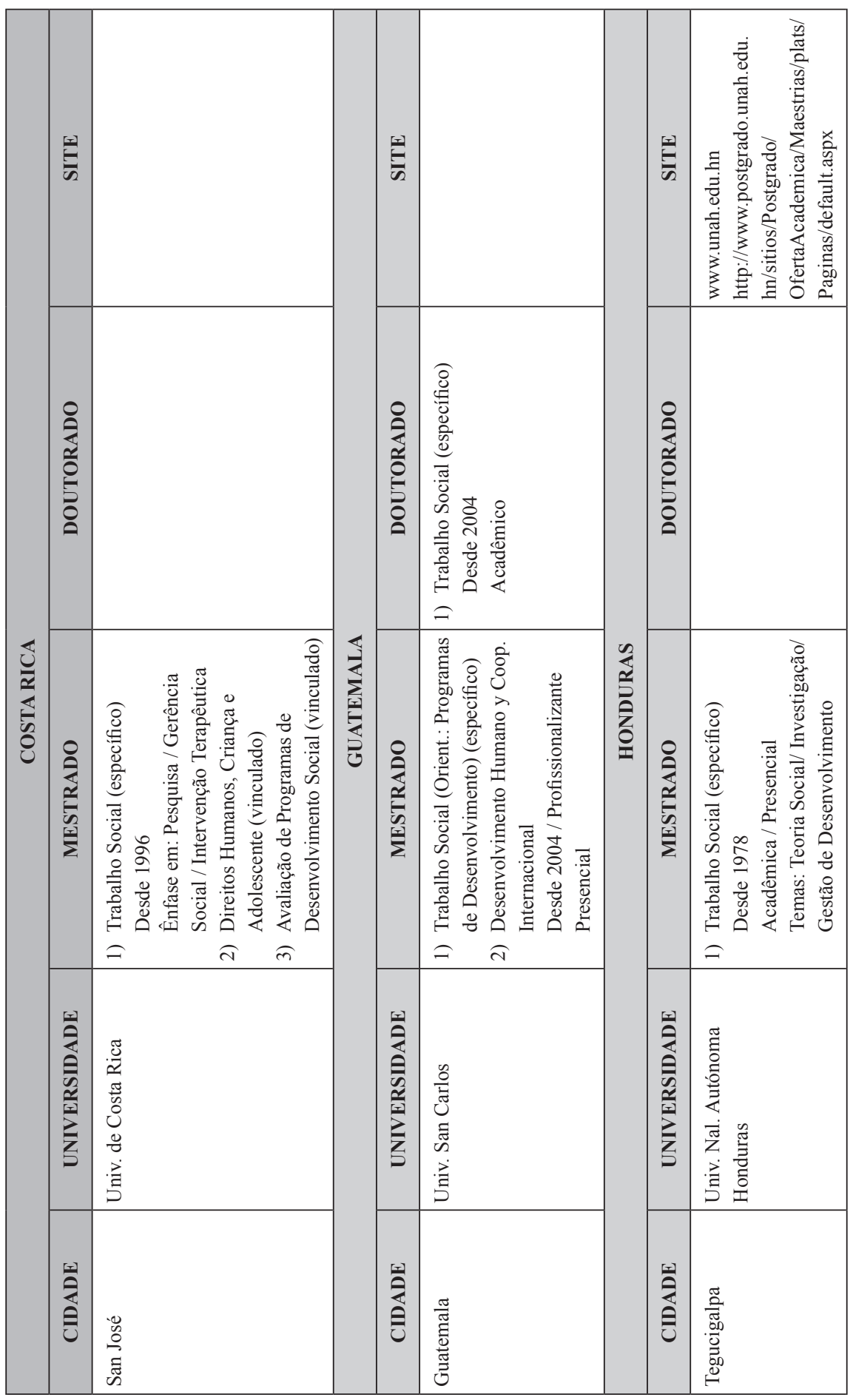




\begin{tabular}{|c|c|c|c|c|c|c|}
\hline $\bar{E}$ & 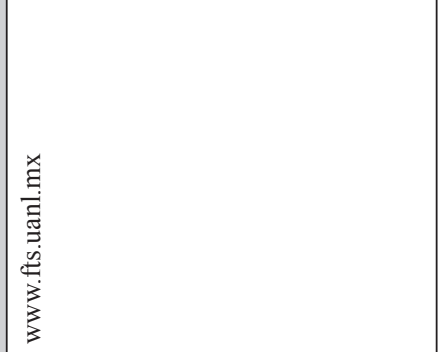 & 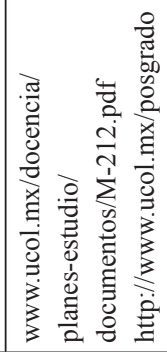 & & & 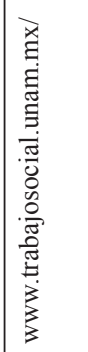 & \\
\hline 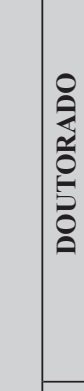 & 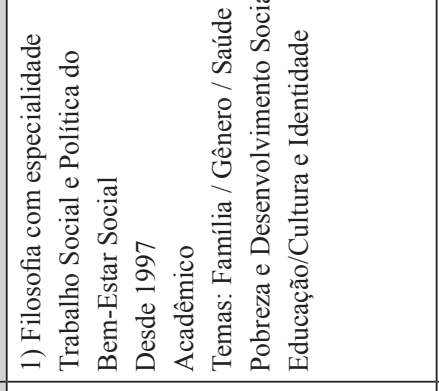 & & & & & \\
\hline 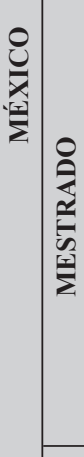 & 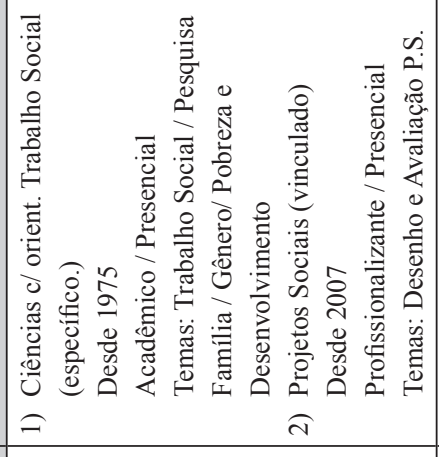 & 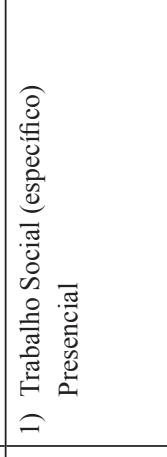 & 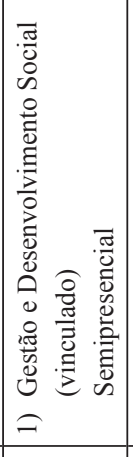 & 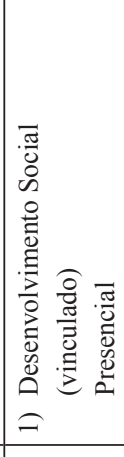 & 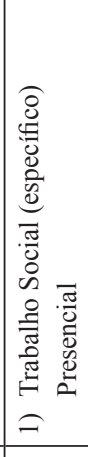 & 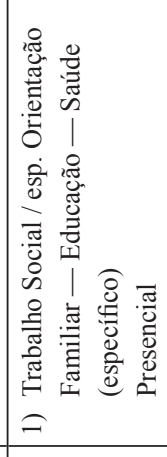 \\
\hline 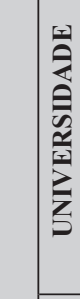 & 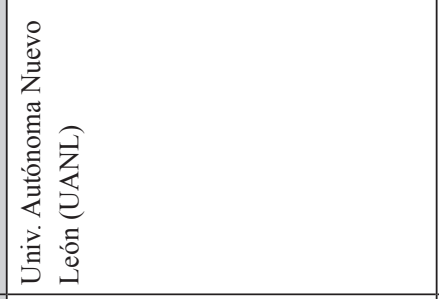 & 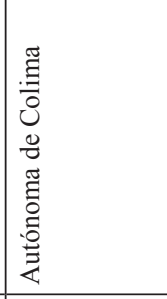 & 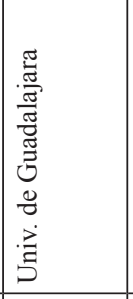 & 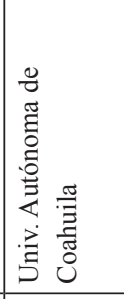 & 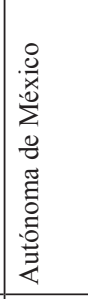 & 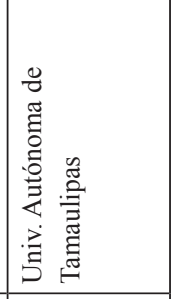 \\
\hline $\bar{z}$ & 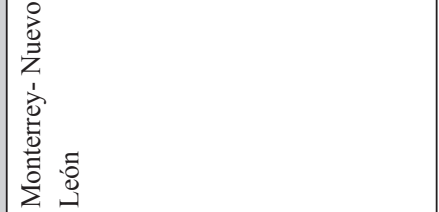 & 言 & 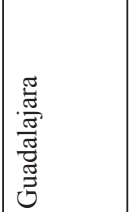 & 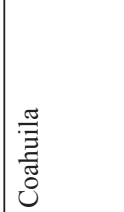 & 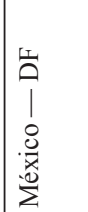 & 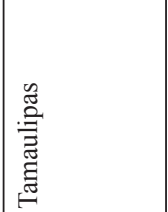 \\
\hline
\end{tabular}




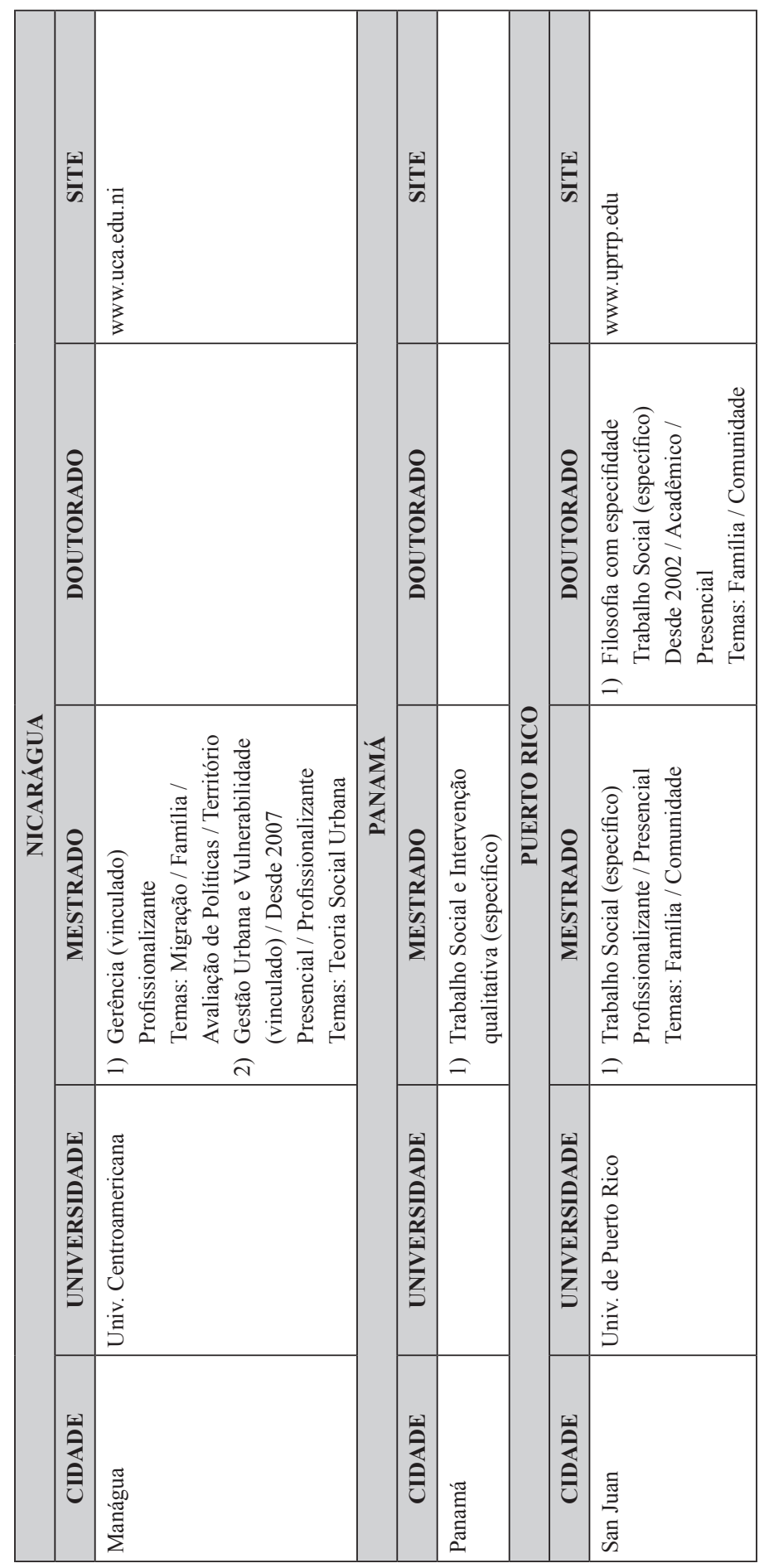

